\title{
Cosmetic Surgery Industry in Brazil: An Assessment Using Cause and Effect Model and Risk Assessment Matrix
}

\author{
Poh-Chuin Teo ${ }^{1}$, Kii Geat Johan Lim², Theresa C.F. Ho ${ }^{3}$, Tan Sim Yin ${ }^{4}$ \\ ${ }^{1,3}$ Azman Hashim International Business School, Universiti Teknologi Malaysia, Malaysia, \\ ${ }^{1}$ E-mail: pohchuin@utm.my (Corresponding author) \\ ${ }^{2,4}$ Tunku Abdul Rahman University College, Malaysia
}

\begin{abstract}
Brazil ranks only second after the United States for the most cosmetic procedures performed in the year 2017. The impressive number of Brazilian cosmetic procedures highlights a profitable market that tends to attract business opportunities to this area. Hence, this study strive to analyze the risk and consequences of cosmetic surgery to physical and mental health as the hidden costs for beauty in Brazil, and recommend areas for improvement to the cosmetic surgery industry in Brazil aimed at combating the issues of surgical failure in the country. Risk and Assessment Matrix was adopted to analyse the risks and consequences of cosmetic surgery to physical and mental health of patients, and the Cause and Effect Model Lastly was employed to identify the possible root causes for Brazilians to risk their life for beauty. The findings showed that the different types of cosmetic surgery complications carry different level of risks and consequences to patients, and the evolving cosmetic surgery trend in Brazil is driven by the factors include culture, cost of offering, growing economy of the country, and celebrity trend. Lastly, recommendations are given to business practitioners and government.

Key words

Cosmetic Surgery Industry, Brazil, Cause and Effect Model, Risk Assessment Matrix

$\begin{array}{ll}\text { Received: } & 15 \text { Mar } 2020 \text { (c) The Authors } 2020 \\ \text { Revised: } & 20 \text { Mar } 2020 \quad \text { Published by Human Resource Management Academic Research Society (www.hrmars.com) }\end{array}$

Accepted: 28 Mar 2020 This article is published under the Creative Commons Attribution (CC BY 4.0) license. Anyone may Published Online: 01 Apr 2020 reproduce, distribute, translate and create derivative works of this article (for both commercial and non-commercial purposes), subject to full attribution to the original publication and authors. The full terms of this license may be seen at: $\underline{\text { http://creativecommons.org/licences/by/4.0/legalcode }}$
\end{abstract}

\section{Cosmetic Surgery Industry: Overview in Brazil}

Cosmetic Surgery refers to the medical and surgical procedures performed for the purpose of enhancing or changing the appearance of a person who is unsatisfied with his or her appearance (myVMC, 2010). The cosmetic surgery industry is estimated to grow at a CAGR of 7.5 percent throughout the forecasted period of 2017 to 2025 (Persistent Market Research, 2017). This represents that the world cosmetic procedure market is gaining popularity and experiencing rapid growth as there is increasing desire for cosmetic surgeries around the world, especially in Brazil.

With a very receptive client base, cosmetic surgery is enjoying a boom in Brazil. Based on a recent statistic published by the International Society of Aesthetic Plastic Surgery (ISAPS), Brazilian plastic surgeons performed almost 7 surgical procedures per 1,000 persons in 2016 . The country ranks only second after the United States for the most cosmetic procedures performed in the year 2017 (ISAP, 2018). The impressive number of Brazilian cosmetic procedures highlights a profitable market that tends to attract business opportunities to this area. 
Brazilian cosmetic surgeons are world renowned as the best in their field (Bernardo, 2017). The high demand of cosmetic surgery in the country enables surgeons to train their skills at all time. Moreover, Brazilian cosmetic surgeons gain global recognition for their daring new techniques in cosmetic surgery (Bernardo, 2017). With a reputation for quality surgeons, low costs, and famous scenic spot, Brazil has developed into one of the world's top destinations for medical tourism (PBB, 2017).

Despite the evolving trend of cosmetic surgery in Brazil drives the country's economy while offering Brazilian the opportunity to become beautiful, the trend do possessed challenges for the country and its citizens. As a country where appearance is seen as central to one's social status, Brazilian is willing to risk everything in exchange for beauty (Jarrin, 2018). Having a body that fits the society's standards is the ideal of beauty among the Brazilian. They will pressure themselves to achieve the desirable standards of beauty in order to gain self-esteem by living in the country.

In addition, surgeons in Brazil are pioneers as there is no legal barrier that could limit them in generating new technologies (Jarrin, 2018). Patients often suffer from side effects of treatments due to improper training of professionals. More to the point, there are only few regulations in place that could protect the lower income patients from malpractice owing to the lenient legal system in Brazil (Bernardo, 2017). Thereby, lower income patients often assumed all the risks since they are lack of financial resources to seek for justice in the case of surgery failure.

As per the issues acknowledged above, the research aims to achieve three objectives:

1. To identify the factors that drives cosmetic surgery to become a trend in Brazil.

2. To analyze the risk and consequences of cosmetic surgery to physical and mental health as the hidden costs for beauty in Brazil.

3. To recommend areas for improvement to the cosmetic surgery industry in Brazil aimed at combating the issues of surgical failure in the country.

In order to achieve the objectives formed above, research frameworks are used to aid in this research. The theoretical framework for this research draws upon three fields. First of all, the model of PEST is conducted to analyze the factors shaping cosmetic surgery trend in Brazil and how the environment alters the perceptions of risks among the Brazilian. Subsequently, in the analysis of risks and consequences of cosmetic surgery to physical and mental health of patients, Risk and Assessment Matrix is applied. Lastly, to identify the possible root causes for Brazilian to risk their life for beauty, the Cause and Effect model is adopted in exchange for solution to the issues.

\section{Literature review}

This study addressed the research objectives, grounded by three theories, namely Cause and Effect model, Risk Assessment Matrix and PEST Analysis. For this research, the analysis of PEST represents an acronym for four factors of change in the environment: political, economic, social, and technological. PEST analysis has various classifications within the literature. PEST analysis remains as the most common form of all PEST variations invented (Peng \& Nunes, 2007). The variations are created by extending the factors of PEST to deliver a more detail analysis (Peng \& Nunes, 2007).

PEST analysis is a strategic planning tool used for investigating the external environments that influence a business or any project (Dcosta, 2017). PEST analysis generally provides an overall idea about the macro environmental conditions as well as the status of a business. By conducting PEST analysis, a business is able to recognize the factors changing and affecting the external environment which might have an impact on the competitive position of the business (Economic Times, 2018). A business is able to make a better business decision upon familiarizing with the external environment.

PEST analysis is a strategic planning tool used for investigating the external environments that influence a business or any project (Dcosta, 2017). PEST analysis generally provides an overall idea about the macro environmental conditions as well as the status of a business (Markwell, 2009). By conducting PEST analysis, a business is able to recognize the factors changing and affecting the external environment which might have an impact on the competitive position of the business (Economic Times, 2018). A business is able to make a better business decision upon familiarizing with the external environment.

Next, Risk Assessment Matrix is required to be well-designed so as to generate liability concerns and deliver awareness on the sense of security (Iomosaic Corporation, 2002). In conducting Risk Assessment 
Matrix, a range of likelihood and consequences are placed as the axes. Range of likelihood and consequences are grouped together to form a ranking for the risks (Bucelli et al., 2018). Likelihood is described as the probability of potential consequences to occur throughout the life of the individuals; whilst, consequence is refers to the impact of the event and the severity of the impact to an individual if it happen (Can \& Toktas, 2018).

In addition, the Cause and Effect Analysis was invented by Professor Kaoru Ishikawa in the 1960s to disclose the causes of a specific event. A cause and effect diagram is a method used to brainstorm graphically on the causes of an issue, observation, problem or event (Otitigde, 2017). Cause and effect diagram is also refers as fishbone or Ishikawa diagram is known for its appearance as the skeleton of a fish. This model is frequently used as a qualitative analysis tool to represent and analyze the causal used in qualitative analysis (Luo et al., 2007).

Risk assessment typically refers to the process of assessing the probabilities and consequences of risks associated with each of the hazards identified (MITRE, 2018). According to Curtis and Carey (2012), risk assessment matrix is made up of three necessary steps: 1) risks identification, 2) risks assessment, and 3 ) respond to risks. They also stated that in identifying the risks associated, a wide net is cast to figure out the nature of risks constitute to the risk profile of certain act. The list of hazards is then requires prioritization so that individual is able to focus and pay attention on the key risks (Levine, 2012). The process of prioritization is accomplished by performing the risks assessment. Identified risks are often assessed in terms of consequences and likelihood (Pfitzer \& Clemens, 2006). Risk is assesses by assigning values to each of the risks through the defined criteria (Can \& Toktas, 2018). Subsequently, the priorities of risk are determined by comparing the level of risk against predetermined target risk levels and acceptance thresholds (Curtis \& Carey, 2012). Finally, the results of risk assessment process are served as primary input to risk response (Curtis \& Carey, 2012). Response options including formulation of response strategy, development of risk response plan and analysis of cost and benefit can be executed by individuals to control and monitor the risks (Levine, 2012).

\section{Methodology of research}

First, Cause and Effect Analysis is applied to study the root causes which drives cosmetic surgery to become an evolving trend in Brazil via constructing of Ishikawa diagram. There are a total of four categories of causes being identified and will be discussed in depth throughout this research. Each categories of cause is made up by primary and secondary reasons that contribute to the corresponding effect of evolving cosmetic surgery trend in Brazil.

In terms of Risk Assessment Matrix, five levels for identification of likelihood and five levels for identification of consequence is employed in this study. The likelihood levels can be described as the probability or with regard to the chances for a person to endure a threat. For each danger or undesirable incident, the most appropriate probability value is used in order to estimate the likelihood for the danger. The consequence levels are described as consequences for the patient or with regards to the severity of consequences. For each danger or undesirable incident, the most appropriate description is used to assess the consequence level for the danger.

Lastly, PEST analysis is used to analyze the factors shaping cosmetic surgery trend in Brazil and how the environment alters the perceptions of risks among the Brazilian. There is a vast range of political, economic, social, technological, and competition factors shaping the cosmetic surgery industry in Brazil.

\section{Findings and discussions}

Firstly, the results based on PEST Analysis, Brazil is ranked as high political risk country. According to a report published by AMBest in 2017, the transfer of presidential power of Brazil to Vice President Michel Temer in August of 2016, after former President Dilma Rouseff was impeached. However, President Temer has allegedly been involved in a bribery scheme that may jeopardize his ability to serve out the remainder of the term, which will end in October 2018. Hence, domestic political situation in Brazil remains very uncertain. The election to be held in October 2018 renders political environment of the country in further ambiguous. 
In terms of economic factor, a rise in real GDP indicates that Brazil is experiencing a growing economy with a rise in national income. Statistic shows the growth in real GDP in Brazil between 2012 and 2017, with projections up until 2022. After almost a decade of strong growth from 2002 to 2013, Brazil entered into the worst recession in its history in 2015 with -3.55\% of GDP recorded and 2016 with $-3.47 \%$ of GDP documented (Statista, 2018). In 2017, the economy recovered and GDP recorded a 0.98\% progression (Statista 2018). Presently, Brazil is recognized as the eighth largest economy around the world (Statista, 2018). Budgetary adjustment and favorable economic conditions have fostered the recovery (Statista, 2018). The Brazilian economy is anticipated to rebound with an expected growth of $2.26 \%$ in 2018 according to predictions by International Monetary Fund (IMF). The GDP in Brazil is also projected to experience a consistently steady growth rate up to the year 2022 (Statista, 2018).

For social factor, Brazil is currently ranked at $32^{\text {nd }}$ in the most health conscious countries around the world (Sadi, 2018). This typically signifies that the country has a moderately high health consciousness among the citizens. In Brazil, the rising percentage of consumers who are in the middle class is driving the consumer trend towards the care for personal health and wellness as rising income allows the citizens to demand for healthy lifestyle (Sadi, 2018). Although economic condition in Brazil remains vastly challenging, health and wellness in the country continues to grow even though the growth is slower than the previous (MRS, 2017). This demonstrates that the trend of pursuing a healthier lifestyle in Brazil remains stable. However, consumers now are more rational in their purchases. The rising health consciousness among Brazilians is seen as a prospect to reshape the cosmetic surgery trend in Brazil. Brazilians is expected to reconsider the risks and dangers of cosmetic surgery aimed at reducing the probability of patients suffer from consequences of surgical failure.

\begin{tabular}{|c|c|c|c|c|c|}
\hline & \multicolumn{5}{|c|}{ Consequences } \\
\hline & $\begin{array}{l}\text { Insignificant } \\
\text { Any injury or } \\
\text { disease that needs } \\
\text { first-aid treatment } \\
\text { only }\end{array}$ & 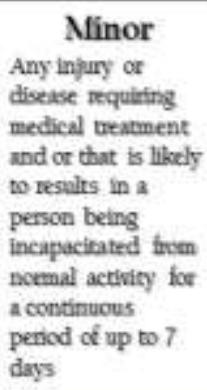 & 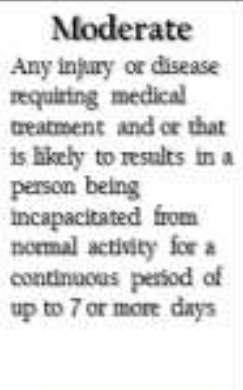 & $\begin{array}{l}\text { Major } \\
\text { A total and } \\
\text { permanent } \\
\text { disability }\end{array}$ & $\begin{array}{l}\text { Catastrophic } \\
\text { Multiple Fatalities }\end{array}$ \\
\hline $\begin{array}{l}\text { Certain } \\
.90 \% \text { Chances }\end{array}$ & & & & & \\
\hline $\begin{array}{l}\text { Likely } \\
50 \%-90 \% \text { Chances }\end{array}$ & & Seroma & & & \\
\hline $\begin{array}{l}\text { Moderate } \\
10 \%-30 \% \text { Chances }\end{array}$ & & & Dissatisfaction & $\begin{array}{l}\text { Nerve } \\
\text { Dumage }\end{array}$ & Blood Loss \\
\hline $\begin{array}{l}\text { Unlikely } \\
3 \%-10 \% \text { Chances }\end{array}$ & & Hematoma & $\begin{array}{l}\text { Infection, } \\
\text { Scarring }\end{array}$ & & Organ Dumage \\
\hline $\begin{array}{l}\text { Rare } \\
6 \% \text { Chances }\end{array}$ & & & & & $\begin{array}{l}\text { DVT/PE, } \\
\text { Anesthesia } \\
\text { Complications }\end{array}$ \\
\hline
\end{tabular}

\begin{tabular}{|l|l|}
\hline & Severe Risk \\
\hline & Significant Risk \\
\hline Moderate Risk \\
\hline Minor Risk \\
\hline
\end{tabular}

Figure 1. Findings for Risk Assessment Matrix 
On the perspective of technology, in order to improve the situation of health care system in Brazil, the people are becoming dependent upon the technology-driven health care services. Several healthcare institutions in Brazil are suggesting that technological innovations in medical and healthcare services greatly help in improving the quality of healthcare (Hempel, 2018). The growing demand for advanced healthcare services has led to the emergence of the digital healthcare market (Hempel, 2018). Considering the above mentioned advancement in the healthcare industry in Brazil, it can be concluded that there is a bright scope for the health technology-driven market in Brazil. As a result, cosmetic surgery market in Brazil could be benefited since cosmetic surgery is treated as a form of healthcare by the Brazilians.

In terms of research findings based on Risk Assessment Matrix, Figure 1 illustrates the consequences of cosmetic surgery complications. The possible complications of cosmetic surgery are analyzed based on the severity and probability in order to classify the risks into ranking comprised of severe, significant, moderate, or minor risk. According to the reports released by International Society of Aesthetic Plastic Surgery (ISAPS) in 2017, the top 10 most common cosmetic surgery complications comprised of hematoma, nerve damage, infection, Deep Vein Thrombosis and Pulmonary Embolism, scarring, general appearance dissatisfaction, organ damage, Anesthesia complications, Seroma, and blood loss (ISAPS, 2017).

The use of Cause and Effect Model in identifying the root causes that potentially contribute to the evolving cosmetic surgery trend in Brazil generated the subsequent results. The findings are presented in Figure 2. The origins of factors contribute to the evolving cosmetic surgery trend in Brazil are derived from four major aspects which include the culture, cost of offering, growing economy of the country, and celebrity trend in Brazil.

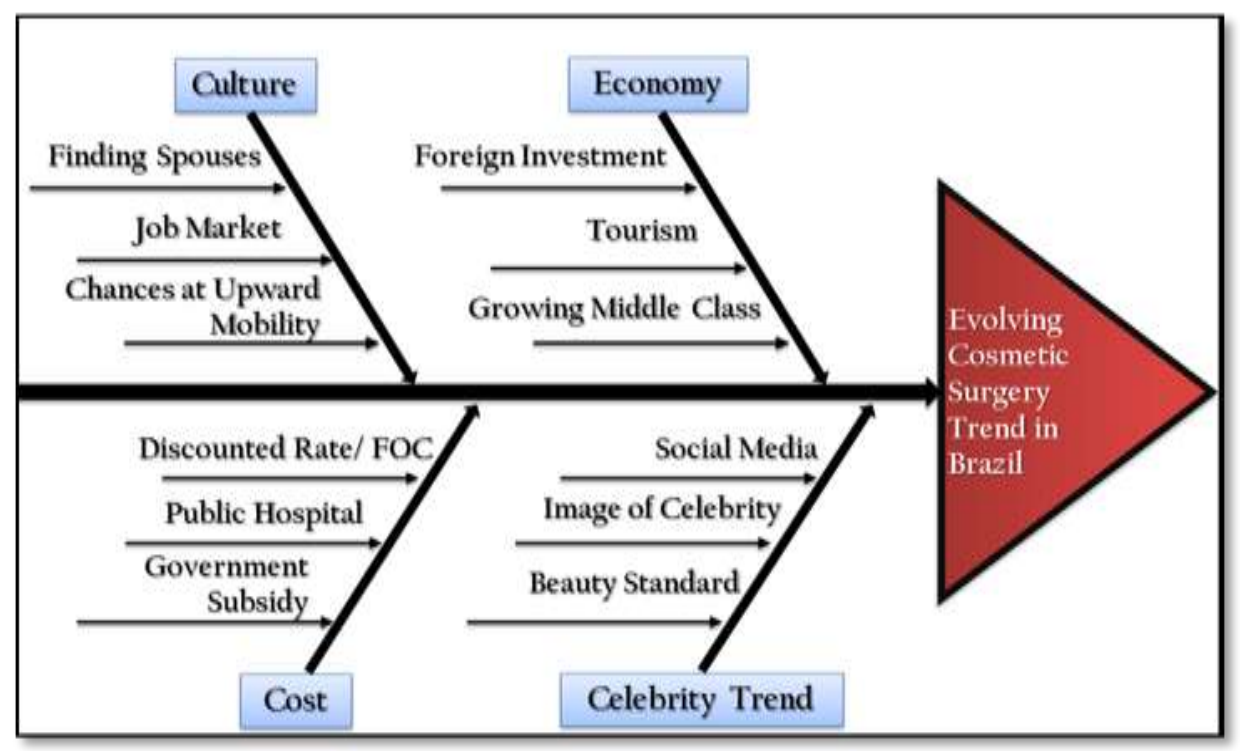

Figure 2.Findings for Cause and Effect Model

\section{Conclusions}

The cultures of Brazil turn out to be the chief root for cosmetic surgery to become an evolving trend in Brazil. The society of Brazil is made up of a mixture of races and ethnicities, making the country rich in diversity, which made social class in Brazil is uniquely different from those of other countries as the country classified social status of citizens based on their physical appearances and skin colour (Commisceo Global, 2017). In Brazil, social discrimination on the basis of skin colour is treated as a common occurrence, in which there is a belief that persons of white skin tone are more beautiful, more intelligent, and more powerful than persons of darker features (Ian, 2015). Therefore, skin lightening as one of the most popular cosmetic procedure in Brazil is still widely practiced among the Brazilians despite the danger of possible side effects (Ian, 2015).

Secondly, the government of Brazil places full support to the right of being beautiful by subsidizing the cost of cosmetic surgery operated in Brazil, which made Brazil ranked at second for the most cosmetic 
surgery performed within a year, whereby approximately 1.2 million of surgeries have been carried out in the country in 2017 (Erlich, 2012). Among 1.2 million of cosmetic surgeries performed, Brazilian government subsidizes approximately half of a million of the surgeries annually; particularly subsidies provided by Brazilian government are allocated in public hospital aimed at reducing the cost of Brazilian cosmetic surgery (Erlich, 2012). The efforts contributed by Brazilian government fulfilled the notion that beauty is a basic right for everyone in Brazil as everyone is able to enjoy the right for being beautiful regardless of income level. In other parts of the world, the cost of cosmetic surgery might be outrageous especially as cosmetic surgeries are not enclosed by the purchase of insurance. Owing to the notion that beauty is a basic right similar to right for healthcare, Brazil evolved into the best destination in the world for tourism of aesthetic (Stylist, 2011).

Thirdly, the bright prospect for economic growth in Brazil attracts the significant Foreign Direct Investment (FDI) into the country and stimulates greater flows of venture capital and long term financing (Kinsey, 2014). The economic growth and development have led to the emergence of a rising middle class, with increased disposable income (Klein et al., 2018). The massive increase in middle class makes middle income group to become the biggest social group in Brazil with a total of 113 million people in 2017, which represent for more than $50 \%$ of the total population across the country (Klein et al., 2018). As compared with the emerging middle classes in other BRIC countries, middle class in Brazil are recognized as a 'world middle class', due to the capability of middle class in Brazil to purchase is greatly higher as compared with purchasing capability of middle classes in other countries (Sennes, 2017). With an increasing income level and purchasing power, the more Brazilians will have the ability to afford for cosmetic surgery. As a result, the industry of cosmetic surgery flourishes owing to the increasing involvement among Brazilians.

Last but not least, celebrity trend is also one of the main contributors. In Brazil, a country famed for its passion with the body beautiful, people are increasingly opting for surgery aimed at improving their appearance (Supanet, 2017). Social media in particular is having a huge impact on the industry of cosmetic surgery. As of 2017, Brazil is the fourth largest internet market with a user base of 139,111,185, placing penetration around $66 \%$ (Translate Media, 2018). With a great level of social media penetration, Brazilians are bombarded with the images of celebrities and the lavish and enviable way they live their lives, in which the idea of beauty in the perceptions of Brazilians will be influence by the image of celebrities where they can be easily discovered on the social media. The gorgeous image of celebrity portrayed on the social media, is often perceived as the ideal appearance for Brazilians and by imitating the physical appearance and the way celebrities live, the Brazilians feel secure as beautiful for them means looking alike with the celebrities (Allure Plastic Surgery, 2015). As according to a plastic surgery center in Brazil, it is relatively common for a patient to come in with a photo of a celebrity asking to replicate the nose, eyes, lip, or bust line of a particular star (Plastic Surgery Centre of Nashville, 2018).

\section{References}

1. Allure Plastic Surgery. (2015). Celebrity Beauty Ideals and Plastic Surgery Trends: 30 Years of Influence. Retrieved July 17, 2018], from https://www.newyorkplasticsurgeryallure.com/blog/celebritybeauty-ideals-and-plastic-surgery-trends-30-years-of-influence.html.

2. Bernardo, N. (2017). State of Plastic Surgery in Brazil. Retrieved June 9, 2018, from https://www.ncbi.nlm.nih.gov/pmc/articles/PMC5889431/.

3. Bucelli, M., Paltrinieri, N., \& Landucci, G. (2018). Integrated risk assessment for oil and gas installations in sensitive areas. Retrieved June 20, 2018, from https://ac-els-cdncom.tarcez.tarc.edu.my/S0029801817307576/1-s2.0-S0029801817307576-main.pdf?_tid=0634f1c7-a41a45ef-950e-d69d2fc7abad\&acdnat=1534238232 fba9c47b10547da7f06390d02363b023.

4. Can, G., \& Toktas, P. (2018). A novel fuzzy risk matrix based risk assessment approach. Retrieved June 20, 2018, from https://www-emeraldinsight-com.tarcez.tarc.edu.my/doi/pdfplus/10.1108/K-12-20170497.

5. Commisceo Global. (2017). Brazil Guide. Retrieved July1, 2018 fromhttps://www.commisceoglobal.com/resources/country-guides/brazil-guide. 
6. Curtis, P., \& Carey, M. (2012). Risk Assessment in Practice. Retrieved June 20, 2018, from https://www2.deloitte.com/content/dam/Deloitte/global/Documents/Governance-Risk-Compliance/dttlgrc-riskassessmentinpractice.pdf.

7. Dcosta, A. (2017). Components of a PESTLE Analysis. Retrieved June 24, 2018, fromhttps://www.brighthubpm.com/project-planning/51754-components-of-a-pestle-analysis/.

8. Erlich, N. (2012). For Brazil, Beauty Is Serious Business. Retrieved July 8, 2018, fromhttps://www.cnbc.com/id/46869525.

9. Hempel (2018). Digital healthcare market in Brazil and role of healthcare startups. Retrieved July 18, 2018, from https://www.dr-hempel-network.com/health-policies-in-india/digital-healthcare-market-inbrazil/.

10. Ian G.-K. (2015). Plastic Paradise: Brazil's Cosmetic Surgery Boom. Retrieved July 1, 2018, from http://thepolitic.org/plastic-paradise-brazils-cosmetic-surgery-boom/.

11. ISAPS. (2018). ISAPS Global Statistics. Retrieved July 1, 2018, from https://www.isaps.org/medical-professionals/isaps-global-statistics/.

12. Jarrin, A. (2018). In Brazil, patients risk everything for the 'right to beauty'. Retrieved July 1 , 2018, from https://theconversation.com/in-brazil-patients-risk-everything-for-the-right-to-beauty-94159.

13. Kinsey, M. (2014). Connecting Brazil to the world: A path to inclusive growth. Retrieved July 7 , 2018,

from https://www.mckinsey.com/ /media/McKinsey/Featured\%20Insights/Americas/Brazils\%20path\%20to\%20i nclusive\%20growth/MGI_Connecting_Brazil_to_the_world_Executive_summary_May\%202014.ashx.

14. Klein, C., Mitchell, S., \& Junge, B. (2018). Naming Brazil's previously poor: "New middle class" as an economic, political, and experiential category. Retrieved July 15, 2018, from https://anthrosource.onlinelibrary.wiley.com/doi/full/10.1002/sea2.12104.

15. Levine, E. (2012). Improving risk matrices: the advantages of logarithmically scaled axes. Retrieved July 20, from http://web.a.ebscohost.com.tarcez.tarc.edu.my/ehost/pdfviewer/pdfviewer?vid=1\&sid=2cdc4c15-ffff4adf-ab40-e0067886dbaa\%40sessionmgr4006.

16. Luo, T., Wu, C., \& Duan, L. (2017). Fishbone diagram and risk matrix analysis method and its application in safety assessment of natural gas spherical tank. Retrieved July 16, 2018, from https://wwwsciencedirect-com.tarcez.tarc.edu.my/science/article/pii/S0959652617326410.

17. MITRE. (2018). Risk Impact Assessment and Prioritization. Retrieved July 20, 2018, from https://www.mitre.org/publications/systems-engineering-guide/acquisition-systems-engineering/riskmanagement/risk-impact-assessment-and-prioritization.

18. myVMC (2010). Cosmetic surgery: An introduction. Retrieved July 9, 2018, from https://www.myvmc.com/lifestyles/cosmetic-surgery-an-introduction/.

19. Otitigbe, J. (2017). Fishbone Facilitation Reflection. Retrieved July 16, 2018, from http://web.b.ebscohost.com.tarcez.tarc.edu.my/ehost/pdfviewer/pdfviewer?vid=1\&sid=f491045f-5104467c-9ffe-3a54d1313894\%40sessionmgr104.

20. Patients Beyond Borders. (PBB) (2018). Brazil and Medical Travel. Retrieved December 31, 2018, https://patientsbeyondborders.com/brazil/

21. Peng, G., \& Nunes, M. (2007). Using PEST Analysis as a Tool for Refining and Focusing Contexts for Information Systems Research. Retrieved July 24, 2018, from http://citeseerx.ist.psu.edu/viewdoc/download?doi=10.1.1.464.6692\&rep=rep1\&type=pdf.

22. Persistent Market Research. (2017). Cosmetic Procedures Market to Reach US\$ 51.6 Billion by 2022. Retrieved December 1, 2018, from https://globenewswire.com/newsrelease/2017/09/27/1133602/0/en/Cosmetic-Procedures-Market-to-Reach-US-51-6-Billion-by-2022Persistence-Market-Research.html.

23. Pfitzer, T., \& Clemens, P. (2006). Risk Assessment \& Control. Retrieved July 20, 2018, from http://web.a.ebscohost.com.tarcez.tarc.edu. $\mathrm{my} /$ ehost/pdfviewer/pdfviewer?vid=1\&sid=cfd20def-76d840a5-a85e-20e0151eb037\%40sessionmgr4010. 
24. Plastic Surgery Centre of Nashville. (2018). What Influence do Celebrities have on Plastic Surgery Trends? Retrieved July 18, 2018, from https://www.theplasticsurgerycenterofnashville.com/influencecelebrities-plastic-surgery-trends/.

25. Sennes, R. (2017). Strengthening the Middle Class in a New Brazil. Retrieved July 15, 2018, from http://publications.atlanticcouncil.org/spotlight-new-brazil/.

26. Statista. (2018). Brazil: Growth rate of the real gross domestic product (GDP) from 2012 to 2022 (compared to the previous year). Retrieved July 18, 2018, from https://www.statista.com/statistics/263615/gross-domestic-product-gdp-growth-rate-in-brazil/.

27. Stylist. (2011). Made in Brazil. Retrieved July 15, 2018, from https://www.stylist.co.uk/beauty/made-in-brazil/131639.

28. Supanet. (2017). How Social Media is affecting the Cosmetic Surgery Industry. Retrieved December 15, 2018, from https://www.supanet.com/how-social-media-is-affecting-the-cosmetic-surgeryindustry-a18980.html.

29. The International Society of Aesthetic Plastic Surgery. (2018). ISAPS Global Statistics. Retrieved December 31, 2018, from https://www.isaps.org/medical-professionals/isaps-global-statistics/.

30. Translate Media. (2018). Brazil Social Media. Retrieved July 15, 2018, from https://www.translatemedia.com/translation-services/social-media/brazil-social-media/. 